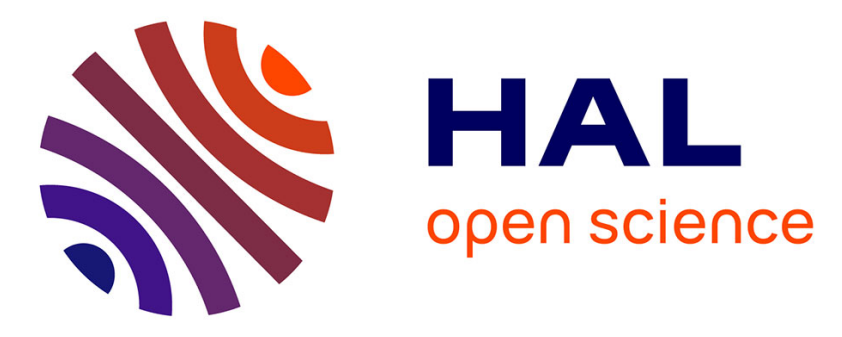

\title{
Cognitive dissonance induced by writing a counterattitudinal essay facilitates performance on simple tasks but not on complex tasks that involve working memory
}

Marie-Amélie Martinie, Thierry Olive, Laurent Milland

\section{To cite this version:}

Marie-Amélie Martinie, Thierry Olive, Laurent Milland. Cognitive dissonance induced by writing a counterattitudinal essay facilitates performance on simple tasks but not on complex tasks that involve working memory. Journal of Experimental Social Psychology, 2010, 46 (4), pp.587-594. 10.1016/j.jesp.2009.10.018 . hal-00747697

\section{HAL Id: hal-00747697 \\ https://hal.science/hal-00747697}

Submitted on 1 Nov 2012

HAL is a multi-disciplinary open access archive for the deposit and dissemination of scientific research documents, whether they are published or not. The documents may come from teaching and research institutions in France or abroad, or from public or private research centers.
L'archive ouverte pluridisciplinaire HAL, est destinée au dépôt et à la diffusion de documents scientifiques de niveau recherche, publiés ou non, émanant des établissements d'enseignement et de recherche français ou étrangers, des laboratoires publics ou privés. 


\section{Accepted Manuscript}

Cognitive dissonance induced by writing a counterattitudinal essay facilitates performance on simple tasks but not on complex tasks that involve working memory

Marie-Amélie Martinie, Thierry Olive, Laurent Milland

PII:

S0022-1031(09)00271-6

DOI:

10.1016/j.jesp.2009.10.018

Reference:

YJESP 2374

To appear in:

Journal of Experimental Social Psychology

Received Date:

7 September 2009

Revised Date:

29 September 2009

Please cite this article as: M-A. Martinie, T. Olive, L. Milland, Cognitive dissonance induced by writing a counterattitudinal essay facilitates performance on simple tasks but not on complex tasks that involve working memory, Journal of Experimental Social Psychology (2009), doi: 10.1016/j.jesp.2009.10.018

This is a PDF file of an unedited manuscript that has been accepted for publication. As a service to our customers we are providing this early version of the manuscript. The manuscript will undergo copyediting, typesetting, and review of the resulting proof before it is published in its final form. Please note that during the production process errors may be discovered which could affect the content, and all legal disclaimers that apply to the journal pertain. 
RUNNING HEAD: Cognitive dissonance and performance

\author{
Cognitive dissonance induced by writing a counterattitudinal essay facilitates \\ performance on simple tasks but not on complex tasks that involve working memory
}

\author{
Marie-Amélie Martinie \\ University of Poitiers, France \\ Thierry Olive \\ CNRS \& University of Poitiers, France \\ Laurent Milland \\ University of Poitiers, France
}

This article examines how performance is facilitated with simple tasks and is impaired with complex ones in individuals experiencing dissonance. Experiment 1 measured the performance of dissonance participants at a simple reaction time task. Reaction times were shortest in the dissonance condition. This facilitation effect was interpreted as resulting from increased arousal with dissonance. In Experiment 2, participants performed a more complex secondary memory task that required to memorize and to recall short and long series of numbers. Participants in the dissonance condition performed less well than participants in the no-dissonance condition only under a high memory load and did not differ with a low load. It is suggested that dissonance requires some working memory resources. Accordingly, it is assumed that the arousal properties of dissonance facilitates performance with simple task that do not involve working memory and require a dominant response, but that dissonance impairs performance with tasks that strongly involve working memory. 


\section{Cognitive dissonance induced by writing a counterattitudinal essay facilitates performance on simple tasks but not on complex tasks that involve working memory}

The present article aims at examining why performance of individuals experiencing dissonance is facilitated in simple tasks but is impaired with complex tasks. According to Festinger (1957), the perception of an incompatibility between an individual's cognitions produces a mental state labeled cognitive dissonance. Dissonance occurs, for instance, when a person freely engages in a behavior that conflicts with his or her thoughts or beliefs. The conditions required to produce dissonance are now familiar and well documented (Abelson, Aronson, McGuire, Newcomb, Rosenberg, \& Tannenbaum, 1968; Harmon-Jones \& Mills, 1999). Two conditions are indispensable to create dissonance: 1) a perceived freedom of choice to engage in counterattitudinal behavior (Brehm \& Cohen, 1962; Wicklund \& Brehm, 1976), and 2) a perceived responsibility for the negative consequences of this behavior (Cooper \& Fazio, 1984).

In addition, dissonance is conceptualized as a motivational state that results from the negative psychological tension aroused by an inconsistency between two cognitions. Festinger (1957) indeed proposed that dissonance is a "motivating factor [for wich] one can substitute notions similar in nature such as hunger" (p. 3). This motivational construct has the same proprieties to those of "drive" within traditional learning theory and, consequently, it is assumed that dissonance has arousal properties. For example, it has been shown that dissonance increases general activity (e.g., Cook, Pallak, Storm, \& McCaul, 1977; Pallak, Brock, \& Kiesler, 1967; Pallak \& Kiesler, 1968) as indicated by the fact that it affects several indicators such as vasoconstriction (Gerard, 1967), heartbeat (Mann, Janis, \& Chaplin, 1969), alpha waves (McMiller \& Geiselman, 1974), galvanic skin responses (Elkin \& Leippe, 1986), and the frequency of non-specific skin conductance responses (Croyle \& Cooper, 1983). As 
dissonance arousal motivates the individual to reduce it by changing one or both of the inconsistent cognitions, several modes of dissonance reduction have been identified, such as attitude change (e.g., Festinger \& Carlsmith, 1959), act rationalization (e.g., Beauvois, Joule, \& Brunetti, 1993), trivialization (e.g., Simon, Greenberg, \& Brehm, 1995) and denial of responsibility (Gosling, Denizeau, \& Oberlé, 2006). The energizing properties of dissonance arousal have also been shown on reduction of dissonance (for reviews, see Fazio \& Cooper, 1983). For example, if arousal is increased by caffeine (Steele, Southwick, \& Critchlow, 1981), or a sports session (Fazio \& Martin, 1981, cited by Fazio \& Cooper, 1983), attitude change increases. By contrast, if dissonance arousal is lessened by alcohol (Steele et al., 1981) or by a tranquilizing drug (Cooper et al., 1978), attitude change is lessened, too.

Conceived in motivational terms and as a drive state, dissonance is expected to facilitate performance on simple tasks that require a dominant response. Since drive energizes all concurrent response tendencies, when a task elicits few competing responses of low strength, as it is the case with simple tasks, the effect of high drive is expected to facilitate performance. Conversely, dissonance should impair performance on more complex task (Pallak \& Pittman, 1972; Waterman, 1969). Indeed, when a task elicits many competing response tendencies (complex task), drive energizes them all and thus performance should be hindered. Waterman (1969) tested this hypothesis by having two groups of participants to write essays on opposite sides of an issue on which opinions were polarized at one end (favoring or opposing arguments). Immediately after that writing task, participants performed a paired-associate learning task that differed in complexity. In the simple task condition, the pairs of words were highly semantically and related with the correct response to each stimulus word relatively dominant and the strength of competing response tendencies was minimal. The complex list, on the other hand, minimized within-pair associations and maximized competing intralist associations. Performance at the simple and complex paired- 
Cognitive dissonance and performance, 4

associate task was then compared. Waterman expected that dissonance would interact with task complexity in that the dissonant group would show better performance than the consonant group on the simple task and poorer performance on the complex task. Analysis of the number of errors during acquisition indicated an interaction between level of dissonance and level of response competition such that the dissonance participants made more errors in the high-response competition list than did the non-dissonance participants. Although there was no effect for dissonance under low-response competition, these results supported the view that dissonance arousal may alter performance in ways unrelated to dissonance reduction. According to Kiesler and Pallak (1976), these findings suggest that "arousal may facilitate incidental retention of stimuli for which either few competing responses or strong associations exist in the repertory of the participants" (p. 1018). Thus, it can be expected that response facilitation should be observed only with simple tasks, where a dominant response is present. By contrast, with high-demanding or complex tasks where no dominant response is present, the effects of arousal should disappear. In that case, no response facilitation should be observed with dissonance.

Actually, task complexity does not exclusively depend on presence of a dominant response, it is confounded with level of engagement of working memory. Indeed, working memory is not required when no response has to be calculated but simply retrieved or activated. However, when multiple possible responses are available, the individual has to decide which response to make and to inhibit alternative responses. This implies that working memory is engaged. Consequently, it s claimed that dissonance should facilitate performance on tasks with dominant responses - which do jot require working memory, but it should be impaired when no dominant response is available because performance do not depend in that case on arousal but on available working memory capacity. 
The two experiments presented in this article were designed to test that hypothesis. For that purpose, we used a dual paradigm, i.e., which required realizing two tasks at the same time. The primary task - composing a counterattitudinal essay - was designed to create dissonance or not according to the choice participants had to engage in. The secondary task was expected to be facilitated or impaired depending on its complexity. Level of complexity of the secondary tasks was manipulated by using a task that little involved working memory in Experiment 1 - a simple reaction time task, whereas it largely involved working memory in Experiment 2 - a memory load task. Moreover, in the latter experiment, two levels of complexity of the secondary tasks were examined.

\section{Experiment 1}

Experiment 1 involved a no-dissonance condition and a dissonance one. In the nodissonance condition, participants were not given the choice of either accepting or refusing to compose a counterattitudinal essay. By contrast, in the dissonance condition, participants were given this choice, which we assumed to be dissonance-inducing (induced-compliance paradigm). To select the topic of the essay participants were to compose, and to be sure that the chosen topic would elicit dissonance, we followed Cooper's (1998) procedure that requires a preliminary step to assess whether or not participants support a specific point of view. From the reading of texts produced by undergraduate students in writing research studies, it appears that all students are against an increase in university tuition fees. We therefore conducted an independent pre-test with 20 undergraduate students from the Poitiers Faculty of Humanities and Arts to measure their attitude toward an increase in tuition fees at their university. They had to rate this increase on a scale ranging from 1 (do not agree at all) to 9 (absolutely agree). The results of this pre-test indicated that students were opposed to such an increase $(M=1.67$, S.D. $=0.74)$. In the three experiments presented in this article, we therefore asked participants to compose an essay in favor of an increase in university fees. 
We assumed that when they were given the choice to compose such an essay, participants would experience cognitive dissonance.

Simultaneously to the composition, participants performed a simple secondary reaction time task to auditory probes. Thus, while participants were composing their essay, signals (beeps) were periodically emitted. Participants were instructed to react as soon as they detected a signal with a dominant response, i.e., a simple pressing reaction to a stimulus. It is important to notice that validity and reactivity of the reaction time task have been extensively studied in the field of writing research and that this method has been demonstrated to be nonintrusive and non-reactive with text composition (Olive, 2004; Olive, Kellogg, \& Piolat, 2002).

Given that the dissonance state has arousal (or drive-like) properties and that the reaction time task proposes a dominant response, it would take the dissonance participants shorter than participants in the no-dissonance condition to respond to the auditory signals. We measured participants' reaction times and also their writing performances in terms of quality of their essays and of writing fluency. The basic dissonance effect was apprehended in their attitude toward an increase in university tuition fees.

\section{Method}

Participants

Fifty students from the Department of Psychology at Poitiers University volunteered to take part in this experiment and were randomly assigned to one of the two experimental conditions. All participants were treated in accordance with ethical standards.

\section{Tasks}

Essay composition. Participants were told to compose a good essay, in an appropriate style and with a clear structure of ideas about an increase in university tuition fees. They were not allowed to make a rough draft and therefore had to write their text directly on the sheet of 
paper. They had twenty minutes to compose their essay. The quality of the essays was measured by means of a questionnaire assessing the organization of the ideas. Two judges who were blind to the experimental condition assessed them on a scale ranging from 1 (lowest quality) to 7 (highest quality) (inter-rater reliability: Pearson's $r=.82, p<.01$ ).

Secondary reaction time task. While they were composing the counterattitudinal essay, both participants in the no-dissonance and dissonance conditions also performed a simple reaction time task. They were instructed to react as rapidly as possible whenever they detected a signal, by clicking on a computer mouse with their non-writing hand. The ScriptKell program (Piolat, Olive, Roussey, Thunin, \& Ziegler, 1999) was used to emit the auditory signal and to record the reaction times (RTs). As is usual with secondary reaction time tasks (Olive et al., 2002; Piolat \& Olive, 2000), in the first phase of the experiment, participants were asked to perform the auditory probe task in a single-task situation. Twentyfive auditory probes were emitted at 5 to 15 -second intervals. The first five RTs were regarded as warm-up signals and were not included in the calculation of the mean baseline RT. This allowed us to control for individual differences in terms of baseline motor reaction by subtracting the participant's mean baseline RT from each RT recorded during the composition of the essay. Analyses were performed on that measure called interference in RT. During the composition phase, auditory probes were emitted at intervals ranging from 15 to 45 seconds.

Attitude measure. In order to avoid resistance to change (e.g., Snyder \& Ebbesen, 1972; Wixon \& Laird, 1976), attitude was measured after the counterattitudinal essay had been composed. Participants had to score their opinion about an increase on a scale ranging from 1 (absolutely against) to 9 (absolutely in favor).

\section{Design and procedure}


After they had given their informed consent, participants were randomly assigned to one of two conditions, which were created by either forcing students to compose the essay (no-dissonance condition) or giving them choice to agree or refuse (dissonance condition). The experimenter told participants that the experiment was about writing and attention. Participants in both conditions were told to compose an essay in favor of a tuition fee increase. All participants began the experiment by performing the auditory probe task in the single-task situation. Next, they composed the essay for 20 minutes while simultaneously responding as quickly as possible whenever they heard an auditory probe. When they had finished composing their text, they were asked to assess their attitude toward a tuition fee increase. After this final phase, participants were told the real purpose of the experiment. Despite the instructions, one participant in the no-dissonance condition composed an essay arguing against a tuition fee increase. Data from this participant were therefore not included in the analyses (final $\mathrm{N}=49$, with 25 participants in the dissonance condition and 24 participants in the no-dissonance condition).

\section{Results}

Attitude. A one-tailed Student's t-test was carried out on the attitude measure. As expected, attitude reliably differed between the two experimental conditions, $t(47)=-4.68, p$ $<.001, P R E=0.31$. Participants in the dissonance condition were more in favor of a tuition fee increase after composing their essay than participants in the no-dissonance condition (see Table 1).

Secondary reaction time task. A one-tailed Student's t-test conducted on the participants' mean baseline RT showed that participants in the dissonance condition $(M=295$ $\mathrm{ms}, S . D .=32 \mathrm{~ms})$ did not differ from participants in the no-dissonance condition $(M=291$ ms, S.D. $=34 \mathrm{~ms}), t(47)<1$. A two-tailed Student's t-test was conducted on the effect of interference on the reaction times (RTs). The means and standard deviations are shown in 
Table 1. Interference in RTs reliably differed between the two groups, $t(47)=2.19, p=.03$, $P R E=0.09$. In keeping with predictions, interference in reaction times was shorter in the dissonance condition than in the no-dissonance one.

Insert Table 1 about here

Writing performance. A two-tailed Student's t-test was conducted on the text quality and writing fluency (words per minute) scores (see Table 1) to test the effect of dissonance. Neither text quality nor writing fluency was affected (respectively $t(47)=1.48, n s$; and $t(47)$ $<1)$ suggesting that production of the counterattitudinal essay was not affected by the choice to compose it.

\section{Discussion}

After composing the essay, participants in the dissonance condition were more favorable to a tuition fee increase. This finding can be interpreted in terms of cognitive dissonance, assuming that participants changed their initial attitude to reduce the psychological discomfort resulting from the conflict between their attitude and their contrasting behavior. One could object that such an interpretation is only valid when participants' initial attitude is measured. However, we chose not to make this measurement in order to avoid the participants' initial attitude becoming more salient prior to their engagement in the counterattitudinal behavior, as this might have made the participants more resistant to dissonance-reducing change. As participants were randomly assigned to the experimental conditions, it is reasonable to assume that their pre-essay attitudes were similar to those of the pre-test participants. If the participants' attitude change observed in the dissonance condition resulted from dissonance reduction, they we would expect them to be more favorable to a tuition fee increase than the pre-test participants. To test that possibility, 
we conducted a one-way ANOVA to compare the no-dissonance and dissonance conditions with data obtained in the pre-test study $(M=1.67 ; S . D .=0.74)$. This analysis was reliable, $F(2,66)=20.34, p<.001, P R E=.34$. As expected, Scheffé's post-hoc test showed that participants in the dissonance condition were more in favor of a tuition fee increase than participants in the pre-test $(p=.0001)$ suggesting that participants in the dissonance condition did indeed change their attitude.

On the other hand, in line with self-perception theory (Bem, 1967, 1972), one could argue that this attitude change resulted not from dissonance but from the fact that participants realized what their true attitude was while writing the essay of their own free choice. Fazio, Zanna and Cooper (1977) showed that cognitive dissonance is applicable only when attitude is discrepant with behavior (i.e., "latitude of rejection"), and that self-perception is applicable only when attitude is congruent with behavior (i.e., "latitude of acceptance"). The low mean attitude of both the pre-test and the no-dissonance participants indicates that all the participants in the present experiment were in a latitude of rejection. Taken together, these results provide compelling evidence that the change in attitude toward an increase in tuition fees of participants in the dissonance condition resulted from that dissonance.

Regarding the effect of dissonance at the simple reaction time task, we expected performance to be facilitated, and that it would therefore take the dissonance participants shorter to react to the signals. As expected, participants experiencing cognitive dissonance reacted faster to the secondary signals than participants in the no-dissonance condition, supporting the assumption that dissonance has energetic properties that increase individuals' arousal. One issue remains to be addressed: does this increase in arousal remain constant throughout the dissonant task? It may indeed be expected that arousal decreases because dissonance is a psychologically aversive experience that prompts individuals to seek ways of reducing it. For example, Joule and Lévèque (1994, cited by Beauvois \& Joule, 1996) found 
that attitude change peaked immediately after composing a counterattitudinal essay. Five minutes later, it had already started to decline, and this trend was even more marked after 20 minutes. Given that dissonance gradually diminishes in the course of the counterattitudinal behavior, we would expect to see an attendant decrease in the level of arousal. More specifically, we would expect the difference in reaction times between the dissonance and nodissonance participants to be greater at the beginning of the behavior than at the end. To test that hypothesis, we divided the writing session into three equal phases and compared the RTs for the first and third phases. This segmentation of the writing process is commonplace in writing research and is based on the assumption that the cognitive processes involved in writing are distributed differently across the writing session (Olive, Kellogg, \& Piolat, 2002). A two-tailed Student's t-test indicated that during the first writing phase, reaction times were shorter in the dissonance condition than in the no-dissonance condition, (dissonance: $M=262$ ms, S.D. $=50 \mathrm{~ms}$; no-dissonance: $M=311 \mathrm{~ms}, S . D .=64 \mathrm{~ms}), t(47)=2.98, p=.004, P R E=$ .15. During the second writing phase, reaction times tended to be shorter in the dissonance condition $(M=273 \mathrm{~ms}, S . D .=64 \mathrm{~ms})$ than in the no-dissonance one $(M=312 \mathrm{~ms}, S . D .=74$ $\mathrm{ms}), t(47)=1.94, p=.057, P R E=.07$. This difference eventually disappeared in the final phase of writing (dissonance: $M=300 \mathrm{~ms}, S . D .=65 \mathrm{~ms}$; no-dissonance: $M=330 \mathrm{~ms}, S . D=$ $83 \mathrm{~ms}), t(47)=1.37, n s$. Accordingly, the effects of dissonance were greatest at the start of the dissonant behavior.

The reaction time task we used is a very simple task, involving just detection of auditory signals and motor programming to respond. A facilitation effect was observed on performance: participants who experienced dissonance responded faster. To examine if performance is impaired with complex tasks that involve high-level cognition (e.g., Pallak \& Pittman, 1972), a more complex secondary task engaging working memory was used in Experiment 2. 


\section{Experiment 2}

In Experiment 2, participants were subjected to a more complex task. They performed a concurrent memory load task, which required them to repeatedly memorize and recall series of digits, by contrast with the reaction time task that only probes them sporadically. Because this task does not involve any dominant response (at each trial a new series of digits had to be recalled), and given that dissonance impairs performance on complex tasks (Pallak \& Pittman, 1972), dissonance participants were expected to recall fewer digits than participants who did not experience dissonance. Memory load task also provides an opportunity to examine the impact of different levels of difficulty by manipulating number of items to recall. According to well-documented findings on memory loads (Cowan, 2005), an effect of size of the load would be observed, with a better performance with a low load. In addition, assuming that dissonance facilitates performance at simple tasks but that it impairs performance at complex ones, a dissonance $\mathrm{x}$ load interaction was predicted, with participants in the dissonance condition being less efficient at the memory task than their no-dissonance counterparts, particularly when it involves a high-load.

The dissonance and no-dissonance conditions were designed following the same rationale as in Experiment 1. Half the participants were given the choice of composing the counterattitudinal essay, while the other half were forced to do so. If the participants' attitude in the dissonance condition after composing the essay was found not to differ from that of the participants in the no-dissonance condition, it would be impossible to know whether this was due to an absence of dissonance or to the fact that the additional resources consumed by the concurrent memory load prevented participants from changing their attitude. To avoid such uncertainty, we therefore included two groups of participants who did not perform the secondary task. Thus, if a difference in attitude was observed between the two groups of 
participants with no memory load, an absence of difference in the conditions with memory load could be ascribed to dissonance.

All participants composed a counterattitudinal essay, but only half the participants realized also the concurrent memory task. All participants that were submitted to the memory load task had to retain a series of 3 (i.e., low-load condition) and 5 digits (i.e., high-load condition) all along the composition. The experimental design thus included as a betweensubjects factor the Condition factor (dissonance, no-dissonance) and as within-subject factors the type of task (composing only, composing plus memory) and size of the memory load (low, high). Attitude toward a tuition fee after participants had composed the counterattitudinal essay was measured, as well as accuracy on the memory load task and writing performance (quality of the essays and writing fluency).

\section{Method}

\section{Participants}

Eighty-eight undergraduate students from the Department of Psychology at Poitiers University volunteered to take part in this experiment. Participants were randomly assigned to one of the four experimental conditions created by crossing the dissonance (dissonance, no-dissonance) and task (no memory load, memory load) factors. Thus, there were 22 participants in each experimental condition.

\section{Tasks}

Participants composed a counterattitudinal essay about an increase in university tuition fees. Two judges who were blind to the experimental condition assessed the organization of ideas on a scale ranging from 1 (lowest quality) to 7 (highest quality) (interrater reliability: Pearson's $r=.72, p<.01)$. Attitudes toward the tuition fee increase were once again assessed after the writing task, on a scale ranging from 1 (absolutely against) to 9 (absolutely in favor). 


\section{Memory load task}

A program specifically developed for the present experiment in Transcript Language (Runtime Revolution) oversaw the presentation of the items and their recall. The memory load task required participants to memorize series of 3 or 5 digits and then to recall each one. The program randomly selected the series and also checked that short and long series were equivalent in number. The first series of digits appeared 5 seconds after participants had begun their composition. Instructions asked participants to memorize each digit separately, without trying to chunk them. Thereafter, participants were frequently interrupted (at intervals of between 20 and 30 seconds) by a beep requiring them to recall the series of digits they had memorized. They typed out the digits on the computer keyboard. Participants were not allowed to recall the last item they had memorized first, but apart from this constraint, the order of presentation was not important. One second after they had indicated that their recall was complete by pressing the enter key, a new series of 3 or 5 digits was presented, each digit being displayed for one second.

The percentage of correct recalls reflected participants' performances on the memory load task. When they recalled a series by giving the last digit first, the recall was deemed to be incorrect. Moreover, when erroneous digits were included in the recalled list of digits, or when some digits were forgotten, the recall was also considered to be incorrect. Accordingly, only series that were recalled in their entirety and which did not begin with the last item were regarded as correct.

\section{Procedure}

After they had given their informed consent, participants were randomly assigned to one of four conditions, which were created either by forcing students to compose the essay or else by giving them the choice to agree or decline, and by asking half of them to perform the secondary memory load task. The experimenter told participants that the study was about 
memory. When participants composed the essay and simultaneously performed the memory load task, they began the experiment by performing the memory load task in a single-task situation. Next, they spent 15 minutes composing their essay. During the composition, participants were told to retain 3 or 5 items. When all participants had finished composing their essay, they were asked to assess their attitude toward a tuition fee increase. After this final phase, participants were told the real purpose of the experiment.

Results

Attitude. In order to test the effect of dissonance manipulation on attitude, a factorial 2 (condition: dissonance vs. no-dissonance) x 2 (task: composing only vs. composing plus memory load) ANOVA was conducted on the attitude measure (see Table 2). As expected, participants in the dissonance condition $(M=3.4$, S.D. $=1.5)$ were more in favor of a tuition fee increase than participants in the no-dissonance condition $(M=2.3, S D=1.1), F(1,84)=$ $14.67, p<.001, P R E=.14$. This analysis did not yield any significant task effect (with memory load: $M=3, S D=1.4$; no memory load: $M=2.7, S D=1.4 ; F(1,84)<1)$ or significant interaction, $F(1,84)<1$.

Insert Table 2 about here

Memory load task. Two mixed 2 (condition: dissonance vs. no-dissonance) x 2 (load: low vs. high) ANOVAs were conducted on baseline and secondary percentages of correct recall, with dissonance as a between-subjects factor and load as a within-subjects factor. First and as expected, participants' baseline performances were better under a low load $(M=98.7$ $\%, S D=4.3 \%)$ than a high one $(M=95 \%, S D=8.3 \%), F(1,42)=8.41, p=.005, P R E=$ .16. There was no other reliable effect, $F s(1,42)<1$. 
The second analysis was conducted on the scores at the memory task. The data are plotted in Figure 1. As expected, participants performed better under a low load $(M=84.4 \%$, $S D=9.3 \%)$ than a high one $(M=66.3 \%, S D=12.2 \%), F(1,42)=89.73, p<.0001, P R E=$ 68. As expected, participants also performed better in the no-dissonance condition $(M=$ $79.2 \%, S D=7.6 \%)$ than in the dissonance condition $(M=71 \%, S D=8.1 \%), F(1,42)=$ $12.14, p<.001, P R E=.22$.

Moreover, a significant interaction was observed, $F(1,42)=4.24, p=.04, P R E=.09$. Post-hoc comparisons with Scheffé's test $(p<.01)$ indicated that under a low load, dissonance participants $(M=81.6 \%, S D=9.6 \%)$ performed as just well as the no-dissonance participants $(M=86.1 \%, S D=8.7 \%)$, but that under a high load, dissonance participants performed less well $(M=60.3 \%, S D=11.1 \%)$ than their no-dissonance counterparts $(M=$ $72.4 \%, S D=10.3 \%)$. Interestingly, a covariance analysis with the baseline scores as covariate provided the same findings, indicating that the participants' baseline scores did not influence how well they performed the task in the dual-task condition.

Insert Figure 1 about here

\section{Writing performance.}

A factorial 2 (condition: dissonance vs. no-dissonance) x 2 (task: composing only vs. composing plus memory) ANOVA was conducted on quality scores and writing fluency (number of words per minute). The means and standard deviations are shown in Table 2. As expected, participants who only had to compose the essay $(M=4.6, S D=1.2)$ reliably produced better texts than participants who also had to perform the memory load task $(M=2$, $S D=1), F(1,84)=126.21, p<.0001, P R E=.60$. No other significant effect was found, $F s(1,84)<1$. 
Regarding writing fluency, as expected, participants composed more words per minute when they did not have to perform the memory load task $(M=14.6, S D=3.9)$ than when they did have to $(M=7.9, S D=2.2), F(1,84)=105.62, p<.001, P R E=.55$. Writing fluency was also greater in the dissonance condition $(M=12.1, S D=5.2)$ than in the nodissonance condition $(M=10.4, S D=3.8), F(1,84)=7.28, p<.01, P R E=.07$. Lastly, this analysis yielded a reliable condition $\mathrm{x}$ task interaction, $F(1,84)=4.81, p=.03, P R E=.05$. More specifically, Scheffé's post-hoc test $(p<.01)$ indicated that participants composed their essay faster when they did not carry out the memory load task, and that this difference was particularly pronounced in the dissonance condition. Moreover, when they did not perform the memory load task, the dissonance participants were more fluent than the no-dissonance ones, whereas this difference disappeared when participants did perform the memory load $\operatorname{task}(p<.001)$.

\section{Discussion}

As in Experiment 1, participants who composed the counterattitudinal essay of their own free choice were more favorable to an increase in tuition fees. This was true not only when participants just composed their essay, but also when they simultaneously performed the memory load task. This indicates that adding the memory load task did not prevent participants from changing their attitude, for example by misattributing their dissonance to the greater difficulty of the dual-task condition.

Regarding the memory load task, as expected, participants performed better under a low load than under a high one. This result is consistent with the literature on memory loads which assumes that with more number of digits to recall, less working memory resources is available, and consequently that performance is better with a low load (e.g., Cowan, 2005). Interestingly, dissonance participants performed less well than no-dissonance participants only when they were submitted to a high-load (a long series of digits). In dual task designs 
such as in Experiment 2, a lower performance is commonly explained in terms of reduced working memory capacity or resources. The difference between dissonance and nodissonance participants at the memory task thus suggests that dissonance consumes working memory resources. Since the dissonance participants had few working memory resources available, they were not able to efficiently manage the composition task and the memory task and they consequently performed less efficiently on the memory load task than the nodissonance participants. Because the effect of dissonance on performance on the memory load task only appears under a high load, dissonance may be expected to consume a few working memory resources.

Apart from the effect of dissonance on memory task, the analysis of participants' fluency in the composition task revealed that dissonance also had an effect on the level of arousal. The dissonance participants composed their essay at a faster rate than the nodissonance ones. This difference was even more pronounced when participants had their full working memory capacity at their disposal (i.e., when they did not have to perform the memory load task). This increase in the number of words produced per minute was convergent with the findings on reaction times in Experiment 1. It did not, however, replicate the absence of difference in writing fluency observed in Experiment 1. Taken together, these findings indicate that an increased level of arousal is associated with dissonance.

Despite the fact that the dissonance participants changed their writing behavior when composing the counterattitudinal essay (i.e., they increased their writing rate) and had fewer working memory resources available, they were able to compose texts that were of a quality equivalent to those composed by the participants in the no-dissonance condition. As writing is a very effortful activity that takes up a considerable amount of working memory capacity (see Olive, 2004, for a review), it is possible to affirm that the writing operations were not qualitatively affected by dissonance because sufficient working memory resources were still 
available to compose the text efficiently. This again supports the idea that although dissonance affects working memory capacity, it nevertheless takes up very few working memory resources.

\section{General discussion}

The present findings first support the idea that dissonance has arousal properties. Results of Experiment 1 -in which dissonance participants responded faster to the auditory probes- can be interpreted in the context of energetic models of cognitive resources that postulate that the level of arousal mediates the total amount of cognitive resources available (see Sanders, 1998, for an example). When arousal is either very low or very high, fewer resources are available to individuals and their performance is correspondingly poorer. By contrast, when there is a moderate increase in arousal, performance is facilitated because more resources are available. The faster reaction times of the dissonance participants in Experiment 1 were due to an increase in arousal. Interestingly, dissonance participants only responded faster at the reaction time task at the beginning of writing; by the time they reached the end of their composition, they were just as fast, but no faster, than the nodissonance participants. This suggests that arousal returns to its initial level once the counterattitudinal behavior is finished and attitude change has taken place.

This increase in the level of arousal surely explains why dissonance improves performance in simple tasks but not in complex ones. In complex tasks that involves highlevel cognition and where strategic knowledge is elicited (e.g., Cottrell \& Wack, 1967; Waterman \& Katkin, 1967), individuals engage explicit and conscious processes that require considerable working memory capacity for computing the multiple operations necessary to perform these tasks. Accordingly, a simple, perceptual secondary task with a dominant response such as the reaction time task used in Experiment 1 can demonstrate the facilitation effect of arousal. 
By contrast, complex tasks, in which no dominant response is available, are not impacted by level of arousal because they rely on working memory. The task we used in Experiment 2 clearly engaged working memory and had no dominant response since participants had to constantly recall a new different series of digits. With that task, participants who experienced dissonance did not perform better; they performed less well than participants who did not experience dissonance, but only with a high load. According to a common explanation in the working memory field, individuals experiencing dissonance performed less well because they presumably had less working memory capacity available. In other words, this finding indicates that dissonance consumes extra resources from working memory. This may appear to contradict Lieberman, Oschsner, Gilbert and Schacter (2001) who found that under cognitive load, dissonance participants displayed just as much attitude change as control participants. However, there are differences between Lieberman et al.'s study and our own which may explain these apparently contradictory findings. As secondary task, Lieberman et al. (2001) asked their participants to count the number of low-pitch beeps in different series of beeps. It is possible that this task does not make enough substantial demands on working memory. Participants had indeed to engage perceptual processes in order to detect the lowest pitch tones, and to remember their previous count. This task is actually very similar to a low memory load. More important, Lieberman et al. (2001) did not analyze performances on this secondary task. Without this measurement, it is not possible to rule out an interpretation in terms of working memory capacity, as the possibility that the dissonance participants performed less well on the secondary task cannot be excluded.

There is evidence in the literature that a reduction in the availability of cognitive resources can affect a variety of sociocognitive tasks. For example, the age-related reduction in cognitive resources can affect causal attribution, social vigilance, social judgment biases and attitude change (Wang \& Chen 2006); as does stereotype threat (Beilock \& Carr, 2005; 
Beilock, Ridell, \& Connel, 2007; Croizet, Desprès, \& Gauzin, 2004; Schmader \& Johns, 2003; Schmader, Johns, \& Forbes, 2008). One phenomenon that can explain this reduction in working memory capacity is that dissonance creates intrusive thoughts that are irrelevant to the task in hand but are related to the management or reduction of this discomfort. For example, individuals confronted with dissonance may wonder why they agreed to perform a task they are against, or may brood over their agreement to take part in the experiment, or may try to find thoughts that justify their behavior or make them change their attitude. These intrusive thoughts siphon off some resources from the ongoing task by taking up involuntary working memory capacity to inhibit them (Engle et al., 1999; Rosen \& Engle, 1998, Wegner, 1994). They may not only interfere with the processing of the ongoing task but also distract the subject's attention from the task in hand.

It is important to notice that dissonance impaired performance in the memory task only under a high load. In the low load condition, it is likely that increase of arousal and the supplementary working memory resources needed by dissonance reciprocally cancelled. Only effects of available working memory resources remained. Dissonance thus appears to take up only a small amount of additional resources. This is consistent with Lieberman et al.'s (2001) proposal that "attitude change requires some minimal amount of attention, conscious awareness, or mental effort” (p. 139). Consistently, a recent study by Martinie and Larigauderie (2007) confirmed that attitude change and trivialization are effortful processes, and that attitude change is more effortful than trivialization. Because controlled processes require working memory resources, individuals involved in a counterattitudinal behavior could be expected to experience greater cognitive effort than individuals who do not undergo dissonance. This finding is consistent with the results of Gawronski and Strack (2004) who showed that dissonance affects explicit but not implicit attitudes, the former involving effortful processes and the latter automatic ones. 
To conclude, energetic models of cognitive resources offer a frame to link the findings on arousal of dissonance and reduction in working memory resources. These models relate the amount of cognitive resources available to general physiological activation, namely arousal, postulate. It is assumed that a moderate increase in the level of arousal frees up more cognitive resources. Conversely, a decrease in arousal due, for example, to drugs or to fatigue, reduces the amount of resources available (Humphreys \& Revelle, 1984; Kahneman, 1973; Sanders, 1983, 1998). Given the effects of dissonance on learning (Pallak \& Pittman, 1972), and on increment postbehaviour arousal (Elkin \& Leippe, 1986), it is possible to argue that dissonance increases the level of arousal, which in turn facilitates responses at simple tasks. However, this facilitation effect of dissonance disappears with more complex task that requires large cognitive resources since dissonance also consumes resources. 


\section{References}

Abelson, R. P., Aronson, E., McGuire, W. J., Newcomb, T. M., Rosenberg, M. J., \& Tannenbaum, P. H. (1968). Theories of cognitive consistency: A sourcebook. Chicago: Rand McNally.

Beauvois, J.-L., \& Joule, R. V. (1996). A radical dissonance theory. London: Taylor \& Francis.

Beauvois, J.-L., Joule R. V., \& Brunetti, F. (1993). Cognitive rationalization and act rationalization in escalation of commitment. Basic and Applied Social Psychology, 14, $1-17$.

Beilock, S., \& Carr, T. (2005). When high-powered people fail: Working memory and 'choking under pressure' in math. Psychological Science, 16, 101-105.

Beilock, S. L., Rydell, R. J., \& McConnell, A. R. (2007). Stereotype threat and working memory: Mechanisms, alleviation, and spill over. Journal of Experimental Psychology: General, 136, 256-276.

Bem, D. J. (1967). Self-perception: An alternative interpretation of cognitive dissonance phenomena. Journal of Personality and Social Psychology, 74, 183-200.

Bem, D. J. (1972). Self-perception theory. In L. Berkowitz (Ed.), Advances in experimental social psychology (pp. 1-62). New York: American Press.

Brehm, J., \& Cohen, A. (1962). Explorations in cognitive dissonance. New York: Wiley.

Cook, D., Pallak, M., \& Storms, M., \& McCaul, K. (1977). The effect of forced compliance on attitude change and behavior change. Personality and Social Psychology Bulletin, $3,71-74$.

Cooper J. (1998). Unlearning cognitive dissonance: Toward an understanding of the development of dissonance. Journal of Experimental Social Psychology, 34, 562-575. 
Cooper, J., \& Fazio, R. (1984). A new look at dissonance theory. In L. Berkowitz (Ed.), Advances in experimental social psychology (Vol. 17, pp. 229-266). San Diego, CA: Academic Press.

Cooper, J., Zanna, M., \& Taves, P. A. (1978). Arousal as a necessary condition for attitude change following induced compliance. Journal of Personality \& Social Psychology, $36,1101-1106$.

Cottrell, N., \& Wack, D. (1967). Energizing effect of cognitive dissonance upon dominant and subordinate responses. Journal of Personality and Social Psychology, 6, 132-138.

Cowan, N. (2005). Working memory capacity. London: Psychology Press.

Croizet, J.-C., Després, G., \& Gauzin, M.-E. (2004). Stereotype threat undermines intellectual performance by triggering a disruptive mental load. Personality and Social Psychology Bulletin, 30, 721-731.

Croyle, R. T., \& Cooper, J. (1983). Dissonance arousal: physiological evidence. Journal of Personality and Social Psychology, 45, 782-791.

Elkin, R., \& Leippe, M. (1986). Physiological arousal, dissonance, and attitude change: Evidence for a dissonance-arousal link and a "don’t remind me" effect. Journal of Personality and Social Psychology, 51, 55-65.

Engle, R. W., Tuholski, S. W., Laughlin, J. E., \& Conway, A. R. A. (1999). Working memory, short-term memory and general fluid intelligence: A latent variable approach. Journal of Experimental Psychology: General, 128, 309-331.

Fazio, R., \& Cooper, J. (1983). Arousal in the dissonance process. In J. Cacioppo \& R. Petty (Eds), Social psychophysiology: A sourcebook (pp. 122-152). New York: Guilford Press. 
Fazio, R. H., Zanna, M. P., \& Cooper, J. (1977). Dissonance and self-perception: An integrative view of each theory's proper domain of application. Journal of Experimental Social psychology, 13, 464-479.

Festinger, L. (1957). A theory of cognitive dissonance. Stanford, CA: Stanford University Press.

Festinger, L., \& Carlsmith, J. M. (1959). Cognitive consequences of forced compliance. Journal of Abnormal Social Psychology, 58, 203-210.

Gawronski, B., \& Strack, F. (2004). On the propositional nature of cognitive consistency: Dissonance changes explicit, but not implicit attitude. Journal of Experimental Social Psychology, 40, 535-542.

Gerard, H. (1967). Choice difficulty, dissonance, and the decision sequence. Journal of Personality, 35, 91-108.

Gosling, P., Denizeau, M., \& Oberlé, D. (2006). Denial of responsibility: A new mode of dissonance reduction. Journal of Personality and Social Psychology, 90, 722-733.

Harmon-Jones, E., \& Mills, J. (1999). Cognitive dissonance: Progress on a pivotal theory in social psychology. Washington, DC: American Psychological Association.

Humphreys, M., \& Revelle, W. (1984). Personality, motivation, and performance: A theory of the relationship between individual differences and information processing. Psychological Review, 91,153-184.

Kahneman, D. (1973). Attention and effort. Englewood Cliffs, NJ: Prentice-Hall.

Kiesler, C. \& Pallak, M. (1976). Arousal properties of dissonance manipulations. Psychological Bulletin, 83, 1014-1025.

Lieberman, M. D., Oschsner, K. N., Gilbert, D. T., Schacter, D. L. (2001). Do amnesics exhibit cognitive dissonance reduction? Psychological Science, 12 (2), 135-140. 
Mann, L., Janis, I., \& Chaplin, R. (1969). Effects of anticipation of forthcoming information on predecisional processes. Journal of Personality and Social Psychology, 11, 10-16.

McMiller, G. A., \& Geiselman, R. (1974). Effects of cognitive dissonance on alpha frequency activity: The search for dissonance. Personality and Social Psychology Bulletin, 1, $150-151$.

Olive, T. (2004). Working memory in writing: Empirical evidences from the dual-task technique. European Psychologist, 9, 32-42.

Olive, T., Kellogg, R. T., \& Piolat, A. (2002). Studying text production with the triple task technique: Why and how ? In T. Olive \& C. M. Levy (Eds.), Contemporary tools and techniques for studying writing (pp. 31-58). Dordrecht, The Netherlands: Kluwer Academic Publishers.

Pallak, M., \& Pittman, T. (1972). General motivational effects of dissonance arousal. Journal of Personality and Social Psychology, 21, 349-358.

Pallak, M., Kiesler, C. (1968). Dissonance arousal task evaluation and task performance. Psychonomic Science, 11, 197-198.

Pallak, M., Brock, T., \& Kiesler, C. (1967). Dissonance arousal and task performance in an incidental verbal learning paradigm. Journal of Personality and Social Psychology, 7, $11-20$.

Piolat, A. \& Olive, T. (2000). Comment étudier le coût et le déroulement de la rédaction de textes. Bilan méthodologique. L'Année Psychologique, 100, 465-502.

Piolat, A., Olive, T., Roussey, J.-Y., Thunin, O., \& Ziegler, J.-C. (1999). ScriptKell: A computer-assisted tool for measuring the distribution of time and cognitive effort in writing and other complex cognitive activities. Behavior Research Methods, Instruments, \& Computers, 31, 113-121. 
Rosen, V., \& Engle, R. (1998). Working memory capacity and suppression. Journal of Memory and Language, 39, 418-436.

Sanders, A. F. (1983). Towards a model of stress and human performance. Acta Psychologica, 53, 64-97.

Sanders, A. F. (1998). Elements of human performance: Reaction processes and attention in human skill. Mahwah, NJ: Lawrence Erlbaum.

Schmader, T., \& Johns, M. (2003). Converging evidence that stereotype threat reduces working memory capacity. Journal of Personality and Social psychology, 85, 440452.

Schmader, T., Johns, M. \& Forbes, C. (2008). An integrated process model of stereotype model of stereotype theart effects on performance. Psychological Review, 115, 336356.

Simon, L., Greenberg, G., \& Brehm, J. (1995). Trivialization: The forgotten mode of dissonance reduction. Journal of Personality and Social Psychology, 68, 247-260.

Snyder, M., \& Ebbesen, E. (1972). Dissonance awareness: A test of dissonance theory versus self-perception theory. Journal of Experimental Social Psychology, 8, 502-517.

Steele, C., Southwick. L, \& Critchlow, B. (1981). Dissonance and alcohol: Drinking your troubles away. Journal of Personality and Social Psychology, 41, 831-846.

Wang, M., \& Chen, Y. (2006). Age differences in attitude change: Influence of cognitive resources and motivation on responses to argument quantity. Psychology and Aging, 21, 581-589.

Waterman, C. K (1969). The facilitating and interfering effects of cognitive dissonance on simple and complex paired-associate learning tasks. Journal of Experimental Social Psychology, 5, 31-42. 
Cognitive dissonance and performance, 28

Waterman, C., \& Katkin, E. (1967). Energizing (dynamogenic) effect of cognitive dissonance on task performance. Journal of Personality and Social Psychology, 6, 126-131.

Wegner, D.M. (1994).Ironic processes of mental control. Psychological Review, 101, 34-52.

Wicklund, R., \& Brehm, J. (1976). Perspectives on cognitive dissonance. Hillsdale, NJ: Erlbaum.

Wixon, D. R., \& Laird, J. D. (1976). Awareness and attitude change in the forced compliance paradigm: The importance of when. Journal of Personality and Social Psychology, 34, 376-384. 


\section{Authors' notes}

Marie-Amélie Martinie and Thierry Olive, Centre de Recherches sur la Cognition et l'Apprentissage, Centre National de la Recherche Scientifique (CNRS) \& Université de Poitiers.

Correspondence concerning this article should be addressed to Marie-Amélie Martinie, Centre de Recherches sur la Cognition et l'Apprentissage, Maison des Sciences de l'Homme et de la Société, 99 avenue du recteur Pineau, 86000 Poitiers, France. E-mail: marieamelie.martinie@univ-poitiers.fr. 
Cognitive dissonance and performance, 30

Table 1

Attitude (maximum: 9), interference reaction times, writing fluency (in words per minute) and quality of the participants' essays (maximum: 7) in the no-dissonance and dissonance conditions (Experiment 1).

\begin{tabular}{|c|c|c|}
\hline & \multicolumn{2}{|c|}{ Conditions } \\
\hline & No-dissonance & Dissonance \\
\hline Attitude & $1.9(1)$ & $3.5(1.3) *$ \\
\hline Interference RT & 318 (69) & $278(55) *$ \\
\hline Text quality & 3.7 (1.3) & $4.2(1.6)$ \\
\hline Writing fluency & $13.5(2.2)$ & $14.7(6.3)$ \\
\hline
\end{tabular}

Note: Standard deviations are shown in parentheses. $* p<.05$. 
Cognitive dissonance and performance, 31

Table 2

Attitude (maximum: 9), writing fluency (in words per minute) and quality of the participants' essays (maximum: 7) in the no-dissonance and dissonance conditions, according to the presence or absence of memory load (Experiment 3 ).

\begin{tabular}{lcccc}
\hline & \multicolumn{4}{c}{ Condition } \\
\cline { 2 - 5 } & \multicolumn{4}{c}{ No-dissonance } \\
\hline
\end{tabular}

Note: Standard deviations are shown in parentheses. 
Cognitive dissonance and performance, 32

\section{Figure captions}

Figure 1. Participants' accuracy (percentage of correct recall) in the secondary memory task according to size of the load 
Cognitive dissonance and performance, 33

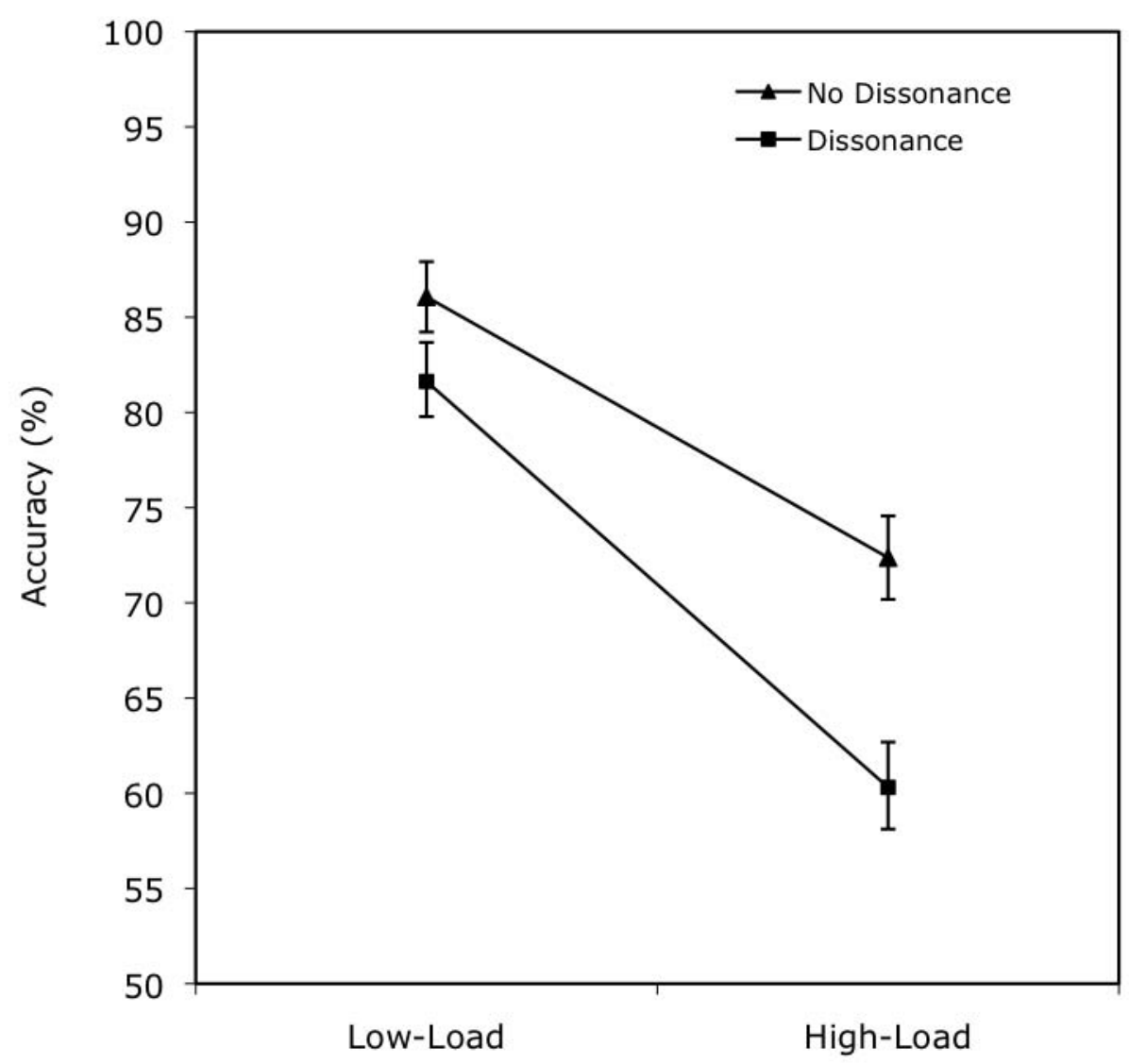

